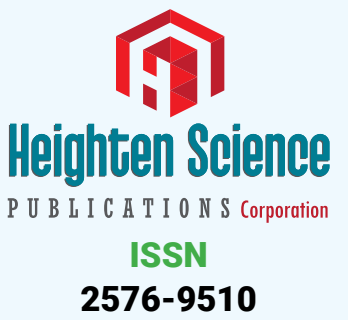

*Address for Correspondence: Luisa Cornegliani DVM, Dipl ECVD, PhD, Ambulatorio Veterinario Associato, c.so Traiano 99/d, 10135 Torino (I), Italy, Email: Icornegliani@libero.it

Submitted: 20 September 2017

Approved: 03 October 2017

Published: 04 October 2017

Copyright: @ 2017 Cornegliani L, et al. This is an open access article distributed under the Creative Commons Attribution License, which permits unrestricted use, distribution, and reproduction in any medium, provided the original work is properly cited.
Research Article

\section{Efficacies of $11 \%$ Lactoferricin and 0.05\% Chlorhexidine Otological Solution compared, in the treatment of microbial otic overgrowth: A randomized single blinded study}

\author{
Luisa Cornegliani*, Federico Leone ${ }^{2}$, Francesco Albanese ${ }^{3}$, \\ Mauro Bigliati ${ }^{4}$, Natalia Fanton ${ }^{5}$ and Antonella Vercelli ${ }^{1}$ \\ ${ }^{1}$ Ambulatorio Veterinario Associato, c.so Traiano 99/d, 10135 Torino (I), Italy \\ ${ }^{2}$ Clinica Veterinaria Adriatica, SS Adriatica Nord 50/1-2, 60019 Senigallia, Ancona (I), Italy \\ ${ }^{3}$ Laboratorio Analisi La Vallonea, via Verdi 39, 73031 Alessano, (LE, I), Italy \\ ${ }^{4}$ Istituto Farmaceutico Candioli, VIA Manzoni 2,10092 Bienasco, Torino (I), Italy \\ ${ }^{5}$ Clinica Veterinaria San Siro, via Lampugnano 99, 20151 Milano (I), Italy
}

\section{Abstract}

Background: Topical therapy with antimicrobial agents is used in otitis treatment. Due to increase of antibiotic resistance, new strategies are needed. Antiseptics are used but they may induce contact dermatitis. Natural antimicrobial peptides may represent future effective drugs.

Objectives: The objectives were to test the efficacy of an $11 \%$ lactoferricin otological solution (LCF) in bacterial and yeasts otic overgrowth and compare LCF with a commercial one containing chlorhexidine (CLX) $0.05 \%$.

Materials and methods: Forty-one dogs diagnosed with bacterial or yeasts otitis overgrowths were included according to general good practice. They were randomly assigned to lactoferricin or chlorhexidine group for treatment. Otological solution were applied twice a day for a week and then daily for another week. Clinical and cytological score was assessed at day 1 and day 14. At the end of the study, the owners had to express an opinion on the overall efficacy of the products. Statistical analyses were performed using Wilkoxon's test and T test for paired samples. Results in lesional and cytological score were significative with a $p<0.05$.

Results: Forty dogs completed the study. All cases, receiving lactoferricin or chlorhexidine, were successfully treated with clinical signs remission and regression of infection $(p<0.05)$. The owners' judgment was good in $87 \%$, mild in $13 \%$ for LCF group. For CLX they scored good in $41 \%$, mild in $24 \%$ and unuseful in $35 \%$ of cases.

Conclusions: Lactoferricin, an antimicrobial natural peptide, showed the same efficacy of chlorhexidine in the treatment of otitis characterized by bacterial or/and yeast overgrowth.

\section{Introduction}

Skin infection and otitis related to bacteria and/or yeast are common in dogs with allergic skin diseases [1]. Furthermore other dermatological condition, as for example primary or secondary seborrhea, may lead to surface pyoderma and otitis [1]. In the last decades, the use of systemic and topical antibiotics has been associated with increased bacterial resistance in men and animals [2-6]. When surface or superficial bacterial infections are present, topical treatment may be the best choice, because it is generally safe and could have a good efficacy if properly applied [2,3,7]. Historically the use of chlorhexidine (CLX) is generally related to its proved efficacy in skin bacterial and yeast infections in dogs, as in other species [8]. In dogs many otologic products 
are available to treat otitis when bacterial or yeasts overgrowth is identified $[2,8,9]$. In these formulations CLX is present at $0.5-0.05 \%$ concentrations to avoid oto-toxic effects $[2,10,11]$. Chlorhexidine is safe and clinical cases of irritant, contact dermatitis or drug reactions are anecdotally reported [4,9]; conversely in human being, the use of topical chlorhexidine based disinfectants may induce severe skin reactions at different concentrations [12-15].

Lactoferricin, a lactoferrin derived peptide, has a well known antimicrobial efficacy in vivo and in vitro $[16,17]$. It is used in farm animals and men as topical or systemic antibacterial, antifungal and antiviral therapy [16-18]. In dogs there are few reports about its efficacy as antibacterial topical solution [19]. The aims of this study were to evaluate the efficacy of a lactoferricin topical otologic commercial product in bacterial and/or Malassezia spp. overgrowth, and to compare it with a chlorhexidine commercial topical otologic product.

\section{Materials and Methods}

This study involved client owned dogs and was performed based on good clinical practice guidelines practice by national Gazzetta Ufficiale [(G.U.) n²89; 10-12-1996, 47-53, Italy].

\section{Study design}

This was a prospective, randomized, controlled, single-blinded comparative study. The objectives were: to evaluate the efficacy of an otological solution containing lactoferricin (LCF) $11 \%$, verbascoside $0.1 \%$ and glycerophosphoinositol lysine $2 \%$ (Candioli, Italy) in otitis related to bacterial and yeast overgrowth; to compare it with another otological solution with chlorhexidine (CLX) 0.05\%, lactic and salicylic, propilenic glycol (ICF, Italy). Four referral practices with a different geographic location in national territory were involved in the study. Four dermatologists were involved in the study and each of them had 10 clinical cases to select and control before and after treatment.

\section{Subjects}

Client-owned dogs with recurrent bacterial or yeast otitis were eligible for this study. The subjective inclusion criteria were: presence of erythematous and ceruminous external ear canal otitis, absence of thimpanic membrane rupture, cytology diagnosis for bacterial or Malassezia spp. overgrowth ( $>10$ at 400X), absence of inflammatory cells, protein or nuclear material at cytological examination. Thimpanic membrane integrity was assessed by video-otoscopic examination. Furthermore owner's written informed consent for the inclusion in the trial and treatment was mandatory.

Exclusion criteria were any other condition for which other topical drugs or therapeutical choices had be applied (e.g. purulent otitis, ear mites' otitis, etc). All the dogs do not have received topical treatment in the ear canal at least from 14 days. Diets, ciclosporin, oclacitinib and allergenic specific immunotherapy were permitted if they had been started before the clinical trial.

\section{Trial protocol and experimental design}

At the inclusion visit (day 1), dogs with mono or bilateral otitis according to inclusion/exclusion criteria were selected. If the animals fit all the criteria, they were randomly and blinded assigned to two treatment groups: group LCF (lactoferricin $11 \%$, verbascoside and glycerophosphoinositol lysine; Actea Oto ${ }^{\circledR}$, Candioli, Torino, Italy) and group CLX (chlorhexidine $0.05 \%$, lactic and salicylic acid; Clorexyderm Oto ${ }^{\circledR}$, ICF, Cremona, Italy). All the groups had the same protocol treatment: topical solution, prepared in numbered identical bottles, had to be applied twice a day for 7 days, than once a day for another week. No other topical treatments were permitted during the 
trial. A final control was performed at day 14 . The owners were instructed by written instructions to how perform the therapy at day 1 . No ear cleaning was performed before application of the products. Even the owners did not know the topical product used until the end of the study.

\section{Clinical examination}

Clinical score of the ear canal was performed using a modified CADESI [20] table including a restricted examination of the pinnae and ear canal (Table 1). Erythema, lichenification, excoriation and auto-traumatic lesions of the pinnae were evaluated as: 0 , absence; 1 , mild; 2 moderate; 3 severe (Table 1). The vertical external ear canal was scored with the same scale used for the pinnae. In this case the parameters used were: amount of cerumen in the lumen, erythema, ulcers or erosions. If the last two parameter were identified the animal was excluded from the study. Furthermore the body weight conditions of the enrolled dogs were controlled before and after the topical treatment to identified eventually concurrent discomfort.

\section{Cytology assessment $[2,21]$}

Cytological examination was performed using a cotton swab gently introduced in the ear canal. The samples were obtained at each visit on day 1 and 14. They were smeared in a thin layer on a glass slide and prepared with Romanowsky modified stain (Hemacolor ${ }^{\circledR}$ Merck KGaA, Darmstadt, Germany). Each investigator read the obtained samples at day 1 and 14 . All the stained samples were completely observed at $10 \mathrm{X}$ to identify the eventually presence of inflammatory cells. It they were not identified and the patients were still eligible for the study, every sample was observed at highpower dry field (400x) for keratinocytes, cocci, Malassezia spp. count. For each parameter a media obtained from 10 fields randomly observed at 400x was reported. For keratinocytes was assigned a score as: <5/ 400x: 1; 5-10/400x: 2; 10-20/400x: 3; finally $>20 / 400 x$ : 4 . For bacteria and yeasts the score was: $<10 / 400 x: 1 ; 10-20 / 400 x$ : 2; 20-30/400x: 3; >30/400x: 4 (Table 2).

\section{Owner assessment}

At the end point of the clinical trial (day 14), the owners were asked to complete a single two question survey. Overall satisfaction of the treatment and ease of application were evaluated. Responses were graduated as: excellent, good, mild and unuseful.

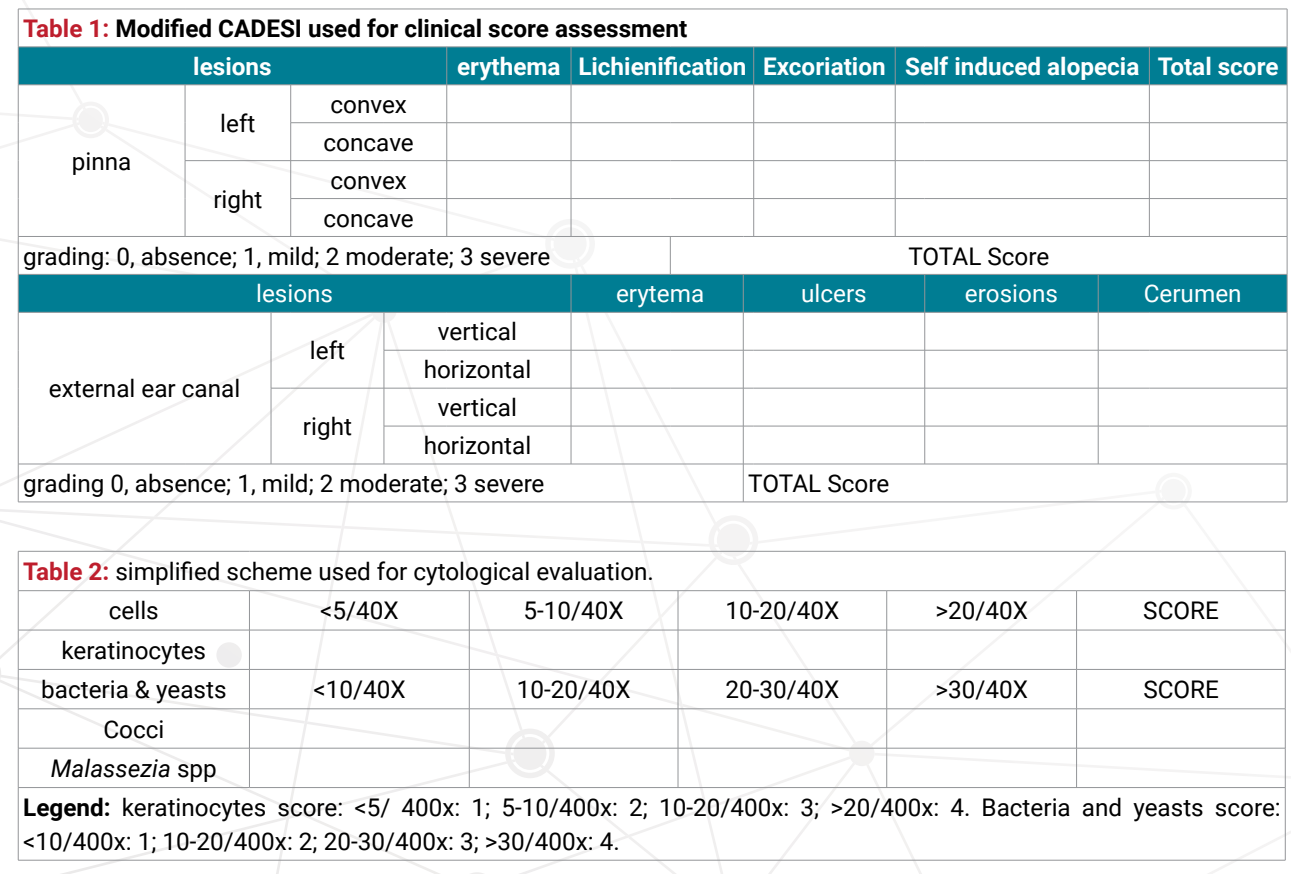




\section{Statistical Analysis}

The statistical analysis was performed with SPSS Statistics 19 software (IBM ${ }^{\circledR}$ UK Ldt; Portsmouth, UK). Shapiro-Wilks test was performed to asses normality of the data and choose the correct analyses. Wilkoxon's test for non parametric data (test for two paired data) was applied. For parametric data was used T test for paired samples. A $\mathrm{p}<0.05$ was considered significative.

\section{Results}

Forty out of 41 dogs enrolled finished the study while one was withdraw due to lack of the owner's compliance. The animals were of different breed and sex with an age between 6 months and 13 years (median 6.3 years) (Tables 3,4).

Twenty-three dogs received LCF otological solution while the other 17 were treated with CLX otological solution. Four of the 23 dogs of LCF group had unilateral otitis, as 3 out of 17 of CLX one. No topical drug reactions were reported in both groups during the study.

\section{Clinical examination}

Erythema of the pinnae decreased in all patients independently of the treatment with a $\mathrm{p}<0.05$, as specifically reported in table 5 . On the contrary, lichenification and self-induced alopecia did not change in group LCF or CLX (Table 6). Excoriation decreased in dogs treated with Lactoferricin with a $p<0.039$. The modified CADESI total score is reported in figure 1, tables 3 and 4 .

The results obtained for external ear canal evaluation had a $\mathrm{p}<0.05$ for erythema and cerumen in both groups (Wilkoxon's test) (Tables 3, 4 and 6, Figure 2). In all the dogs enrolled the body weight conditions did not change during the topical treatment.

\begin{tabular}{|c|c|c|c|c|c|c|c|c|c|}
\hline Breed & Age & Sex & Disease & $\begin{array}{c}\text { Pinna } \\
\text { CADESI } \\
\text { V1 }\end{array}$ & $\begin{array}{c}\text { Pinna } \\
\text { CADESI } \\
\text { V14 }\end{array}$ & $\begin{array}{c}\text { Ear canal } \\
\text { CADESI } \\
\text { V1 }\end{array}$ & $\begin{array}{c}\text { Ear canal } \\
\text { CADESI } \\
\text { V14 }\end{array}$ & $\begin{array}{l}\text { cytological } \\
\text { score V1 }\end{array}$ & $\begin{array}{l}\text { cytological } \\
\text { score V14 }\end{array}$ \\
\hline Akita inu & 1 & $\mathrm{~m}$ & cad & 4 & 0 & 16 & 4 & 5 & 2 \\
\hline French bulldog & 4 & $\mathrm{~m}$ & cad & 3 & 1 & 10 & 2 & 7 & 3 \\
\hline Pit bull & 5 & f & cad & 4 & 2 & 14 & 8 & 5 & 3 \\
\hline French bulldog & 3 & $\mathrm{~m}$ & cad & 2 & 0 & 6 & 2 & 5 & 2 \\
\hline Cocker spaniel & 8 & $f$ & cad & 3 & 1 & 8 & 2 & 5 & 3 \\
\hline Dachshund & 8 & $\mathrm{nf}$ & cad & 8 & 3 & 8 & 4 & 8 & 4 \\
\hline English bulldog & 8 & $\mathrm{~m}$ & cad & 7 & 4 & 20 & 10 & 7 & 3 \\
\hline Maltese & 12 & $\mathrm{~m}$ & cad & 2 & 0 & 16 & 8 & 6 & 3 \\
\hline Boxer & 5 & $\mathrm{~m}$ & cad & 3 & 1 & 16 & 8 & 4 & 2 \\
\hline Lagotto & 0,6 & $\mathrm{~m}$ & arf & 3 & 0 & 16 & 8 & 7 & 4 \\
\hline Mixed breed & 13 & $\mathrm{~nm}$ & unknown & 5 & 3 & 16 & 8 & 6 & 5 \\
\hline WHWT & 6 & $f$ & cad & 16 & 2 & 7 & 2 & 6 & 1 \\
\hline Shitzu & 9 & $\mathrm{~m}$ & cad & 16 & 6 & 20 & 12 & 6 & 8 \\
\hline Sharpei & 2 & $\mathrm{~m}$ & cad & 9 & 2 & 10 & 4 & 5 & 3 \\
\hline Cocker spaniel & 6 & $\mathrm{nf}$ & cad & 18 & 6 & 20 & 8 & 7 & 3 \\
\hline Newfoundland & 12 & nf & cad & 21 & 8 & 16 & 8 & 7 & 3 \\
\hline Beagle & 10 & nf & cad & 10 & 6 & 12 & 8 & 6 & 3 \\
\hline WHWT & 9 & nf & cad & 12 & 6 & 12 & 8 & 6 & 3 \\
\hline Labrador retriever & 2,8 & nf & cad & 2 & 0 & 8 & 0 & 2 & 0 \\
\hline French bulldog & 1 & $f$ & cad + arf & 2 & 0 & 12 & 12 & 8 & 6 \\
\hline Golden retriever & 8 & nf & cad & 6 & 3 & 8 & 2 & 6 & 3 \\
\hline Beagle & 4 & $\mathrm{~m}$ & cad & 4 & 2 & 12 & 8 & 6 & 2 \\
\hline Labrador retriever & 10 & $\mathrm{~m}$ & cad & 4 & 2 & 18 & 8 & 8 & 8 \\
\hline
\end{tabular}


Table 4: signalmen of the included dogs in CLX group. CADESI and general cytological total score are reported before and after treatment with CLX otological product.

\begin{tabular}{|c|c|c|c|c|c|c|c|c|c|}
\hline Breed & Age & Sex & Disease & $\begin{array}{c}\text { Pinna } \\
\text { CADESI } \\
\text { V1 }\end{array}$ & $\begin{array}{c}\text { Pinna } \\
\text { CADESI } \\
\text { V14 }\end{array}$ & $\begin{array}{c}\text { ear canal } \\
\text { CADESI } \\
\text { V1 }\end{array}$ & $\begin{array}{c}\text { ear canal } \\
\text { CADESI } \\
\text { V14 }\end{array}$ & $\begin{array}{c}\text { cytological } \\
\text { score V1 }\end{array}$ & $\begin{array}{c}\text { cytological } \\
\text { score V14 }\end{array}$ \\
\hline Mixed breed & 8 & $\mathrm{~m}$ & $\mathrm{cad}$ & 16 & 8 & 20 & 12 & 8 & 4 \\
\hline Mixed breed & 10 & $\mathrm{nf}$ & $\mathrm{cad}$ & 14 & 8 & 12 & 8 & 5 & 2 \\
\hline WHWT & 12 & $\mathrm{f}$ & $\mathrm{cad}$ & 2 & 1 & 8 & 3 & 6 & 2 \\
\hline Cocker spaniel & 5 & $\mathrm{f}$ & $\mathrm{cad}$ & 4 & 4 & 18 & 10 & 6 & 4 \\
\hline Mixed breed & 8 & $\mathrm{f}$ & $\mathrm{afr}$ & 4 & 2 & 7 & 2 & 7 & 4 \\
\hline Bull terrier & 12 & $\mathrm{~m}$ & $\mathrm{cad}$ & 11 & 4 & 16 & 12 & 7 & 5 \\
\hline $\begin{array}{c}\text { Australian } \\
\text { shepherd }\end{array}$ & 1,7 & $\mathrm{f}$ & unknown & 2 & 1 & 14 & 6 & 5 & 4 \\
\hline Mixed breed & 4 & $\mathrm{~m}$ & $\mathrm{cad}$ & 16 & 16 & 20 & 16 & 8 & 8 \\
\hline German hound & 0,4 & $\mathrm{~m}$ & $\mathrm{rac}$ & 2 & 2 & 28 & 16 & 8 & 8 \\
\hline Yorkshire terrier & 0,5 & $\mathrm{f}$ & $\mathrm{rac}$ & 8 & 8 & 12 & 12 & 6 & 6 \\
\hline Mixed breed & 2 & $\mathrm{f}$ & $\mathrm{cad}$ & 3 & 3 & 12 & 12 & 7 & 7 \\
\hline WHWT & 10 & $\mathrm{nf}$ & $\mathrm{cad}$ & 9 & 6 & 24 & 8 & 9 & 4 \\
\hline Cocker spaniel & 12 & $\mathrm{~nm}$ & $\mathrm{cad}$ & 18 & 6 & 16 & 10 & 6 & 4 \\
\hline Labrador retriever & 4,6 & $\mathrm{~m}$ & $\mathrm{cad}$ & 2 & 2 & 8 & 8 & 12 & 8 \\
\hline Mixed breed & 2 & $\mathrm{~m}$ & $\mathrm{cad}$ & 4 & 4 & 8 & 8 & 4 & 4 \\
\hline German shepherd & 3 & $\mathrm{f}$ & $\mathrm{cad}$ & 8 & 8 & 22 & 22 & 8 & 10 \\
\hline Poodle & 12 & $\mathrm{f}$ & $\mathrm{cad}$ & 6 & 0 & 20 & 9 & 16 & 8 \\
\hline
\end{tabular}

Legend: $\mathrm{nf}$ : neutered female; f: female; $\mathrm{nm}$ : neutered male; $\mathrm{m}$ : male; cad: canine atopic dermatitis; arf: allergic reaction to food; whwt: west highland white terrier.

Table 5: statistical result of modified CADESI score after treatment with LCF or CLX otological product.

\begin{tabular}{|c|c|c|}
\hline Clinical sign & LCF group & CLX group \\
\hline${ }^{\circ}$ Erythema & $\mathrm{P}=0.000$ & $\mathrm{P}=0.001$ \\
\hline *Escoriations & $\mathrm{P}=0.039$ & $\mathrm{P}=0.180$ \\
\hline *Alopecia $^{*} \mathrm{P}=0.071$ & $\mathrm{P}=0.102$ \\
\hline *Lichenification & $\mathrm{P}=0.109$ & $\mathrm{P}=0.999$ \\
\hline
\end{tabular}

Table 6: statistical results of clinical score of the ear canal after treatment with LCF or CLX otological product.

\begin{tabular}{|c|c|c|}
\hline Clinical sign & LCF group & CLX group \\
\hline Erythema* & $P=0.000$ & $P=0.003$ \\
\hline Cerumen $^{\circ}$ & $P=0.000$ & $P=0.001$ \\
\hline
\end{tabular}

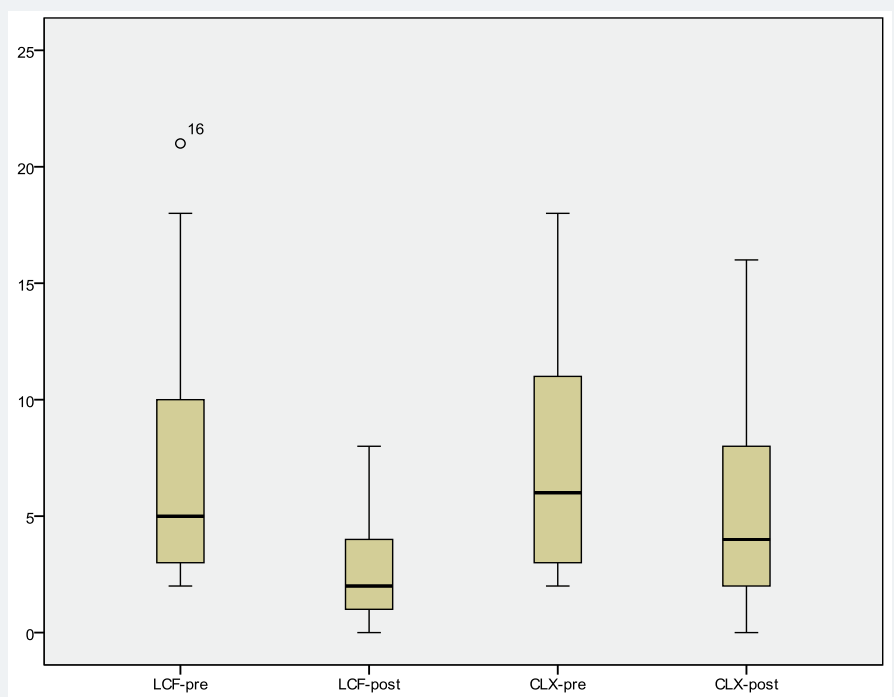

Figure 1: Graph of the modified CADESI values before and after treatment with LCF or CLX.

Legend: LCF pre median 6, confidence interval $95 \%$ 5.08-11.84; LCF post median 2, confidence interval $95 \% 1.55$ 4.11. CLX pre median 6.69, confidence interval 95\% 4.91-10.26; CLX post median 4 , confidence interval $95 \% 2.98$ 6.79 . 


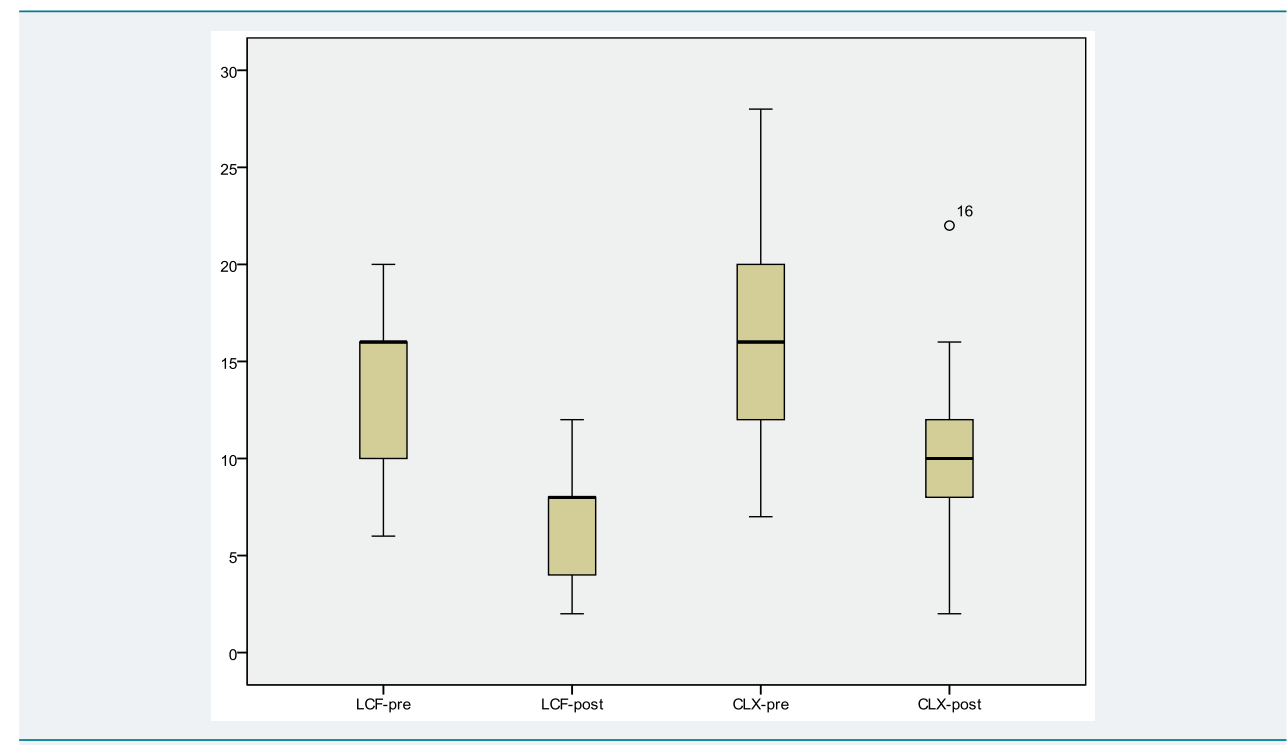

Figure 2: Graph of the modified CADESI values of the ear canal before and after treatment with LCF or CLX Wilkoxon's test.

Legend: LCF-pre median 16, confidence interval 95\% 11.18-15.99; LCF-post median 8, confidence interval $95 \% 4.71$

7.86. CLX-pre median 16, confidence interval 95\% 12.39-18.78; CLX-post median 10, confidence interval $95 \% 7.74$ 12.73 .

\section{Cytology assessment}

Total amount of keratinocytes, cocci and Malassezia spp. decreased in 35/40 dogs independently from the treatment with LCF or CLX solution. For both group the p was $<0.05$ (Tables 3, 4 and 7, Figures 3 and 4).

\section{Owner assessment}

The owners gave different results on overall satisfaction of the treatment. For group LCF, they assigned good results in $87 \%$, mild in $13 \%$; whereas for group CLX they scored good $41 \%$ of cases, mild $24 \%$ and unuseful $35 \%$. The ease of application was scored as follow: group LCF, good in $83 \%$ and mild in $17 \%$; group CLX, good in $65 \%$ and mild in $35 \%$.

\section{Discussion}

The otological 11\% lactoferricin solution showed the same efficacy of one with CLX at $0.05 \%$ in bacterial and Malassezia overgrowth. In dogs, microbial skin or otologic infections can be recurrent if primary causes are unidentified and corrected $[1,2]$. These conditions are often treated with topical and/or systemic antibiotics or antimicotic drugs. All the dogs included were affected by allergic diseases, primarily canine atopic dermatitis and had received many different topical therapies (data not showed).

In canine otitis externa, systemic antimicrobials are unlikely to achieve therapeutic concentrations in the exudate present in the infected ear canal. On the contrary, local antimicrobial therapy, including flushing with antiseptic products alone or in association with topical antibiotics, is the recommended treatment [4,7]. Topical antiseptic products used for management of canine otitis, may contain different molecules with antimicrobial activity, such as triz-EDTA, chlorhexidine, etc. Chlorhexidine is a biguanide compound that exerts bactericidal activity on both Gram-positive and Gram-negative bacteria by membrane disruption [8]. In veterinary medicine, local treatment with $\mathbf{2 \%}$ chlorhexidine was reported to be successful as an alternative or complimentary approach to antibiotic treatment of meticillin-resistant Staphylococcus pseudintermedius infections in small animals [6]. Even in Malassezia dermatitis or otitis, chlorhexidine showed efficacy [2,7,8,22]. In this clinical trial, CLX solution efficacy was confirmed as expected. 
Table 7: cytological evaluation: statistical result for each cytological parameter examined (400x) post treatment.

\begin{tabular}{|c|c|c|}
\hline Cytology & LCF group & CLX group \\
\hline Cocci & $\mathrm{P}=0.011$ & $\mathrm{P}=0.038$ \\
\hline Malassezia spp. & $\mathrm{P}=0.002$ & $\mathrm{P}=0.023$ \\
\hline Keratinocytes & $\mathrm{P}=0.000$ & $\mathrm{P}=0.033$ \\
\hline Wilkoxon's test applied for non parametric data. & \\
\hline
\end{tabular}

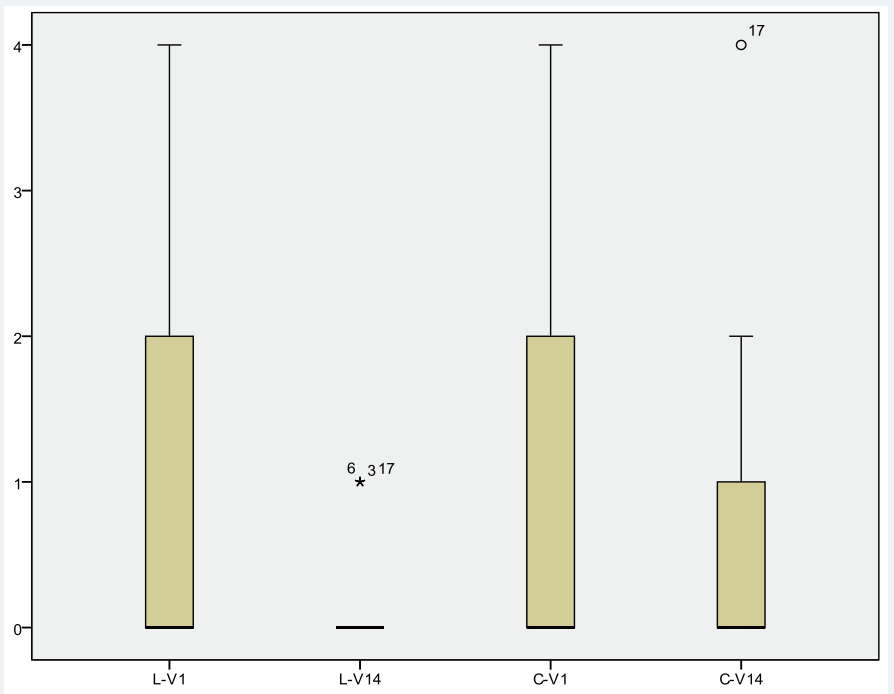

Figure 3: Graph of the bacterial count before and after treatment with LCF or CLX.

Legend: LCF-pre, median 0.89, confidence interval 95\% 0.25-1.52; LCF-post, median 0.22 , confidence interval $95 \%$ 0.1-0.43. CLX-pre, median 1.06, confidence interval 95\% 0.41-0.71; CLX-post, median 0.65, confidence interval $95 \%$ 0.14-1.16.

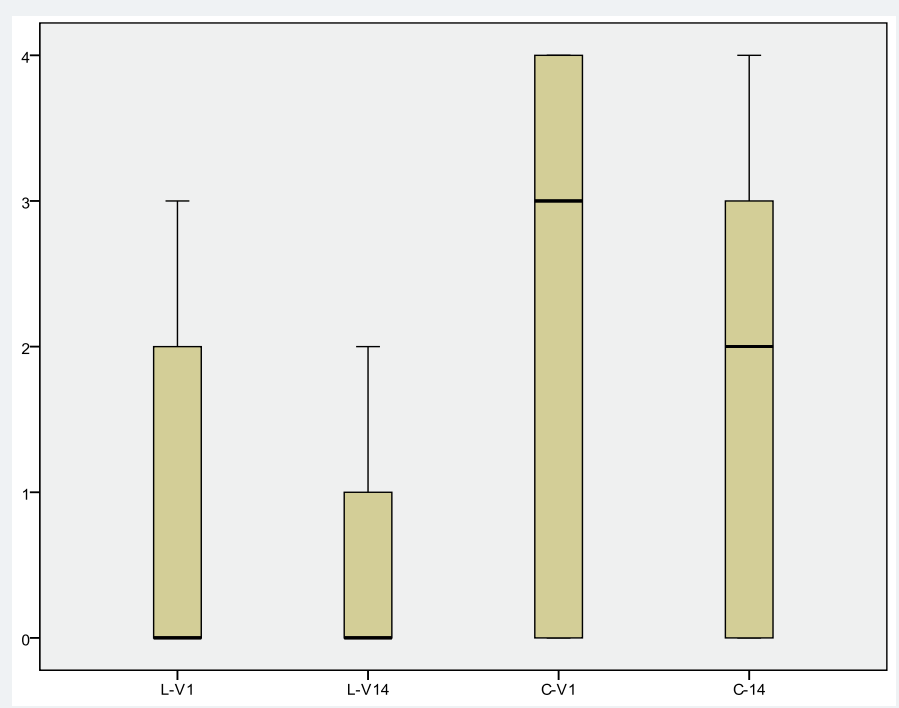

Figure 4: Graph of the Malassezia spp. results before and after treatment with LCF or CLX.

Legend: LCF-pre, median 0.82, confidence interval 95\% 0.27-1.38; LCF-post, median 0.47, confidence interval 95\%

0.15-0.79. CLX-pre, median 2.24, confidence interval 95\% 1.39-3.08; CLX-post, median 1.76, confidence interval $95 \%$ 1.00-2.53.

In human, chlorhexidine topical solution at different concentrations may induce severe irritation, contact dermatitis, urticaria and anaphylactic reactions [14]. It has been well known since the first publication by Calnan in 1962 [23]. Clinical studies showed a sensitization rate of $2 \%$, mainly after repeated applications. This is considered a rather common event in terms of relevance [14,15]. Rarely, even a $0.05 \%$ concentration had induced anaphylactic reaction [15,24]. In most of reported cases, the adverse reaction is limited to the site of application, even if it can extend to other 
areas of the skin. Exceptionally, it can cause photosensitivity, or even a fixed drug eruption [14]. In dogs, rarely anecdotal cases were reported. In man, the diagnosis is confirmed by patch testing at $0.5 \%$ chlorhexidine and/or photo-patch testing [14]; but this has not been evaluated in dogs. In this study, in none of the cases tested side effects were reported or noticed by the veterinarians or owners. In particular, there was no discomfort after application of the otologic product or increase of pruritus and/or erythema.

Recently, due to increase of antimicrobial resistance, natural peptides with antimicrobial activity have been considered for treatment of microbial infections in man and animals [16]. Antimicrobial peptides (AMPs) are a vast group of molecule produced by all living organisms as a natural barrier against infections [16]. Among AMPs, there are bioactive dairy proteins as beta-lactoglobulin or alfa lactoalbumin and lactoferrin (all milk proteins derivates). In man, lactoferrin showed antiviral, antimicrobial, antifungal, anti-parasitic, immunomodulatory and antioxidant activities, alone or in association with other molecules $[16,25]$. Furthermore, lactoferrin has many functional peptides obtained by the action of proteolytic enzymes: lactoferricin (Lfcin) is one of them [16]. The antibacterial activity of Lfcin involves the disordering and alteration of the bacterial membrane permeability which lead to inhibition of macromolecular biosynthesis and finally cell death $[16,26,27]$. The peptide has antibacterial activity in vitro against gram positive and gram negative bacteria, many yeasts and also dermatophytes $[16,28]$. Preliminary reports showed good results in the treatment of surface pyoderma and bacterial and /or yeast otitis $[19,29]$. In this clinical study, the tested solution containing $11 \%$ Lfcin lead to the resolution of the otological problem in a two week treatment. Furthermore, the results were comparable with the CLX control group. This suggests that LCF otological solution has the same efficacy of the CLX one. In particular for bacterial overgrowth, even if the comparative results showed a $\mathrm{p}<0.05$ for both the products, the trend was more favorable for LCF with a $\mathrm{p}<0.001$. Even the number of keratinocytes decreased significantly in LCF group with a $\mathrm{p}<0.000$. These results might be related to the action of natural peptides (e.g. Lfcin) in suppressing the inflammatory effects caused by bacteria [16,29]. We can argue that the natural anti-inflammatory effect of lactoferricin can provide a reduction of erythema and dryness in case of otitis by modifying TEWL (trans epidermal water loss) in allergic dogs. Unfortunately, in this study the TEWL was not checked due to financial limits. The anti-inflammatory effect could be also related to verbascoside (VB) a phenylpropanoid glycoside (PPG), and to glycerophosphoinositol, a substance extracted from the lechitins of sunflower seeds. Verbascoside belongs to a large group of natural polyphenols distributed in the plant kingdom [24]. There is a growing evidence that PPGs, like other plant polyphenols, are powerful antioxidants, either by direct scavenging of reactive oxygen and nitrogen species or by acting as chainbreaking peroxyl radical scavengers [30]. Glycerophosphoinositol is able to intervene within the physiological self-regulation system of the inflammatory cascade that occurs within cells as a result of inflammatory or allergic stimulation [31]. These molecules, as lactoferricin, may decrease the inflammation and perhaps this is the result noticed by the owners. Even if the statistical results were similar, the owners scored the efficacy as good for LCF otological solution with $87 \%$ compared to $41 \%$ of CLX group. The owner gave a blinded assessment because they did not know which was the otological product until the end of the study. Considering the results, LCF solution seems to be more appreciated compared to CLX one. Unfortunately, this is a small study with only 40 dogs involved. This is the limit of many clinical trials where patients are few and their characteristics are often non homogenous. It is often impossible to avoid this bias in clinical practice. In this study, efforts were made to limit the difference between the two groups of treatment. It was not possible to have a homogeneous population represented by at least same breed, age and sex. Cytological examination was the main 
parameter used: absence of inflammatory cells was mandatory as inclusion criteria and so severe cases of otitis were excluded; all the dogs included have more or less the same disease degree. This can be a limit of the study, because only mild cases were studied, but there are no enough laboratories or clinical data to suggest the use of LCF or CLX as a unique therapy in purulent otitis. Furthermore 5/40 dogs did not improve in cytological examination and CADESI parameters. This might be related to the severity of primary allergic disease. In all the cases there was not a worsening of the otic microbial overgrowth or discomfort of the treated dogs.

\section{Conclusions}

Peptides as Lfcin have attracted increasing interest as a new therapeutic natural approach. In the future, there is a hope that they will play a key-role for the broad spectrum of activities as antibacterial and antimycotic natural agent in skin infection control instead of antibiotics. Further clinical studies on use of antimicrobial peptides in dogs and cats are needed to confirm these preliminary reports and eventually add new data on the possible systemic use, as in humans [16].

\section{References}

1. Miller WH, Griffin CE, Campbell KL. Diseases of the eyelids, claws, anal sacs and ears. In Muller and Kirk's small animal dermatology. Elsevier Mosby. St Luis, VII ed. 2013; 724.

2. Jacobson LS. Diagnosis and medical treatment of otitis externa in the dog and cat. J S Afr Vet Assoc. 2002; 73: 162-170. Ref.: https://goo.gl/EHxjCX

3. Nuttal T. Successful management of otitis externa. In Pract. 2016; 38: 17-21.

4. Guardabassi L, Houser GA, Frank LA. Guidelines for antimicrobial use in small animals. In: Guardabassi L, Jensen LB, Hilde K. eds. Guide to Antimicrobial Use in Animals. Oxford: Blackwell Publishing. 2008; 183-120.

5. Laxminarayan R, Duse A, Wattal C, Zaidi AK, Wertheim HF, et al. Antibiotic resistance-the need for global solutions. Lancet. 2013; 13: 1057-1098. Ref.: https://goo.gl/PP9GN9

6. Loeffler A, Linek M, Moodley A, Guardabassi L, Sung JM, et al. First report of multiresistant, mecApositive Staphylococcus intermedius in Europe: 12 cases from a veterinary dermatology referral clinic in Germany. Vet Dermatol. 2007; 18: 412-421. Ref.: https://goo.gl/9BCjjR

7. Morris DO. Medical therapy of otitis externa and otitis media. Vet Clin North Am Small Anim Pract. 2004; 34: 541-545. Ref.: https://goo.gl/Zvdkaf

8. Kuyyakanond T, Quesnel LB. The mechanism of action of chlorhexidine. FEMS Microbiol Lett. 1992; 79: 211-215. Ref.: https://goo.gl/owfTXg

9. Guardabassi L, Ghibaudo G, Damborg P. In vitro antimicrobial activity of a commercial ear antiseptic containing chlorhexidine and Tris-EDTA. Vet Dermatol. 2010; 21: 282-286. Ref.: https://goo.gl/THzmS9

10. Galle HG, Venker-van Haagen, A J. Ototoxicity of the antiseptic combination chlorhexidine/cetrimide (Savlon): effects on equilibrium and hearing. Vet Q. 1986; 8: 56-60. Ref: https://goo.gl/JDPC1r

11. Igarashi $Y$, Oka $Y$. Vestibular ototoxicity following intratympanic applications of chlorhexidine gluconate in the cat. Arch Otorhinolaryngol. 1988; 245: 210-217. Ref.: https://goo.gl/z14mq5

12. Abdallah C. Perioperative chlorhexidine allergy: Is it serious? J Anaesthesiol Clin Pharmacol. 2015 31: 152-154. Ref.: https://goo.gl/hUvJdr

13. Opstrup MS, Johansen JD, Zachariae C, Garvey LH. Contact allergy to chlorhexidine in a tertiary dermatology clinic in Denmark. Contact Dermatitis. 2016; 74: 29-36. Ref.: https://goo.gl/h5EEJn

14. Lachapelle JM. A comparison of the irritant and allergenic properties of antiseptics. Eur J Dermatol. 2014; 24: 3-9. Ref.: https://goo.gl/GkSS7U

15. Colagiuri GF, Di Leo E, Trautmann N, Ferrannini A, Vacca A. Chlorhexidine hypersensitivity: a critical and updated review. J Allergy Ther. 2013; 4: 4-10. Ref.: https://goo.gl/jNzJMK

16. Bruni N, Capucchio MT, Biasiletti E, Enrica Pessione, Simona Cirrincione, et al. Antimicrobial activity of lactoferricin-related peptides and applications in human and veterinary medicine. Molecules. 2016; 21: 752. Ref.: https://goo.gl/LTKwZH 
17. Cafarchia C, Immediato D, Di Paola G, Magliani W, Ciociola T, et al. In vitro and in vivo activity of a killer peptide against Malassezia pachydermatis causing otitis in dog. Med Mycol. 2014; 52: 350-355. Ref.: https://goo.gl/MMSu9K

18. Yin C, Wong Jh, Ng TB. Recent studies on antimicrobial peptides lactoferricin and lactoferrampin. Curr Mol Med. 2014; 4: 1139-1154. Ref.: https://goo.gl/H1zGLv

19. Vercelli A, Fanton N, Bruni N, Vergano D, Bigliati M, et al. Use of lactoferricin, verbascoside and glycerophosphoinositol emulsion in otitis externa treatment: a pilot study. Veterinaria. 2015; 29: 4957. Ref.: https://goo.gl/UbnT6p

20. Nuttall T, Bensignor E. A pilot study to develop an objective clinical score for canine otitis externa. Vet Dermatol. 2014; 25: 530-537. Ref.: https://goo.gl/Uo1QFu

21. Ginel JP, Lucena R, Rodriguez JC, Ortega J. A semiquantitative cytological evaluation of normal and pathological samples from the external ear canal of dog and cats. Vet Dermatol. 2002; 13: 151-156. Ref.: https://goo.gl/PLPfmb

22. Negre A, Bensignor E, Guillot J. Evidence-based veterinary dermatology: a systematic review of interventions for Malassezia dermatitis in dogs. Vet Dermatol. 2009; 20: 1-12. Ref.: https://goo.gl/bTURvp

23. Calnan CD. Contact Dermatitis from drugs. Proc R Soc Med. 1962; 55: 39-42. Ref.: https://goo.gl/QfkijD

24. Porter BJ, Acharya U, Ormerod AD, Herriot R. Latex/chlorhexidine-induced anaphylaxis in pregnancy. Allergy. 1998; 53: 455-457. Ref.: https://goo.gl/rtijXc

25. Dashper SG, Liu SW, Reynolds EC. Antimicrobial peptides and their potential as oral therapeutic agents. Int J Pept Res Ther 2007; 13: 505-516. Ref.: https://goo.gl/yZnzfm

26. Guilhelmelli F, Vilela N, Albuquerque P, Derengowski Lda S, Silva-Pereira I, et al. Antibiotic development challenges: the various mechanisms of action of antimicrobial peptides and of bacterial resistance. Front Microbiol. 2013; 4: 1-12. Ref.: https://goo.gl/jT2WSY

27. Brandenburg K, Schürholz T. Lack of new anti-infective agents: Passing into the pre-antibiotic age? World J Biol Chem. 2015; 26: 71-77. Ref.: https://goo.gl/Qk6MNe

28. Corona A, Vercelli A, Bruni N, Cornegliani L. In vitro bactericidal activity of lactoferricin and other enzymes on bacteria selected from dogs with pyoderma. Vete Dermatol. 2016; $27: 54$.

29. Cornegliani L, Corona A, Vercelli A: Use of lactoferricin, verbascoside and glycerophosphoinositole lysine emulsion in bacterial and yeast overgrowth treatment: a pilot study in ten dogs. Vet Dermat. 2016; $27: 72$.

30. Afanasev IB. Superoxide and nitric oxide in pathological conditions associated with iron overload: the effects of antioxidants and chelators. Curr Med Chem. 2005; 12: 2731-2739. Ref.: https://goo.gl/UDCHY3

31. Vertuani S, Beghelli E, La Scalambra E, Malisardi G, Copetti S, et al. Activity and stability studies of verbascoside, a novel antioxidant, in dermo-cosmetic and pharmaceutical topical formulations. Molecules. 2011; 16: 7068-7080. Ref.: https://goo.gl/isMrk4 